\title{
The Challenge and Value of Applying 'Subjective Interpretation' with Bayesian Network Analysis in Arts and Cultures
}

\author{
Nguyen Minh Hoang \\ International Cooperation Policy, Graduate School of Asia Pacific Studies \\ Ritsumeikan Asia Pacific University \\ 1-1 Jumonjibaru, Beppu, Oita 874-8577 Japan \\ Email: nmhhg8@gmail.com \\ Le Tam Tri \\ International Cooperation Policy, Graduate School of Asia Pacific Studies \\ Ritsumeikan Asia Pacific University \\ 1-1 Jumonjibaru, Beppu, Oita 874-8577 Japan \\ Email: tamtle17@apu.ac.jp
}

Fukuoka, September 15, 2019

\begin{abstract}
Art and Culture are very important aspects of humanity. However, due to their abstract nature, attempts to quantify the value of such fields have been the challenges for the scientific community. Recently, a new work of Vuong et al. (2019) presents an approach that sheds light on the possibility of applying Bayesian networks analysis to clarify the connection between architecture, for example, the design of the house façade and cultural evolution in Vietnamese city in the early 20th century.
\end{abstract}

Coding and creating a database in Social Sciences and Humanities have long been practiced to explore the patterns and information from ageless sources, such as folklore, rituals, norms, religions, and institutions (Turchin et al., 2019; Vuong et al., 2018; Whitehouse et al., 2019). However, the paper of Vuong et al. (2019) provides a new but plausible approach to construct the data of cultural evolution through subjective interpretation. Through this approach, the authors find evidence from the Franco-Chinese house designs in Vietnam to support their study of cultural evolution, an elusive phenomenon in the course of history.

The practice of this method can be applied to examining relevant abstract values. For instance, replicating to the procedure used in the study of architectural designs of old houses in Vietnam, the exploration of cultural evolution can be expanded to other cultural values among society such as folk songs and traditional music. For that reason, the new approach can be a promising tool in bridging understanding from both sides: physically measurable data and data of intangible, subjective feeling. Through the examination and interpretation of the change of subjective perception upon art and beauty throughout history, the culture of our society can be reflected in a clearer way. 
There is still one thing that should be taken into consideration. That is whether the practice of this method limited by the condition of the research target? In fact, when studying about the cultural evolution of humanity, especially in more ancient time, the physical objects (architectures, e.g.) and intangible properties (folk music, e.g.) in most cases are partially lost and forgotten. In contrast of the scarcity and loss of research targets from the ancient time, the research targets in the modern time are usually complemented from multiple different or similar cultures, which greatly increase the complexity for interpretation. As a result, the subjective interpretation of these targets will be incorrect and distorted in both cases.

By being able to overcome the struggles when dealing with the research target, the approach constructing data through interpretation might be an immensely useful tool for social scientists, especially when employing Bayesian networks analysis (La \& Vuong, 2019). The final remark should be made on the type of abstract information and data used in the study. The data exemplify emerging opportunities in considering other elusive, yet historically rich, reading and artistic phenomena or manifestations in East Asian societies, for which the Bayesian approach will become increasingly powerful and suitable, making science more affordable to both researchers and the public at large (Vuong, 2018). These types of study will also open up interesting debates and re-considerations of previously performed research studies, under the light of a new quantitative method, such as those in Whitehouse et al. (2019).

\section{References}

La, V.-P., \& Vuong, Q.-H. (2019). bayesvl: Visually Learning the Graphical Structure of Bayesian Networks and Performing MCMC with "Stan." The Comprehensive R Archive Network (CRAN). Available from: https://cran.r-project.org/package=bayesvl

Turchin, P., Whitehouse, H., François, P., Hoyer, D., Alves, A., Baines, J., ... Xie, L. (2019). An introduction to Seshat: Global History Databank [Preprint]. https://doi.org/10.31235/osf.io/394w2

Vuong, Q. H. (2018). The (ir) rational consideration of the cost of science in transition economies. Nature Human Behaviour, 2(1), 5. https://doi.org/10.1038/s41562 017-0281-4

Vuong, Q.-H., Bui, Q.-K., La, V.-P., Vuong, T.-T., Ho, M.-T., Nguyen, H.-K. T., ... Ho, M.-T. (2019). Cultural evolution in Vietnam's early 20th century: A Bayesian networks analysis of Hanoi Franco-Chinese house designs. Social Sciences \& Humanities Open, 100001. https://doi.org/10.1016/j.ssaho.2019.100001

Vuong, Q.-H., Bui, Q.-K., La, V.-P., Vuong, T.-T., Nguyen, V.-H. T., Ho, M.-T., ... Ho, M.-T. (2018). Cultural additivity: Behavioural insights from the interaction of Confucianism, Buddhism, and Taoism in folktales. Palgrave Communications, 4(1). https://doi.org/10.1057/s41599-018-0189-2

Whitehouse, H., François, P., Savage, P. E., Currie, T. E., Feeney, K. C., Cioni, E., ... Turchin, P. (2019). Complex societies precede moralizing gods throughout world history. Nature, 568(7751), 226-229. https://doi.org/10.1038/s41586-019-1043-4 